\title{
Axillary ultrasound and fine-needle aspiration cytology to predict clinically relevant nodal burden in breast cancer patients
}

\author{
Isabela Panzeri Carlotti Buzatto, Francisco José Cândido dos Reis, Jurandyr Moreira de Andrade, \\ Tamara Cristina Gomes Ferraz Rodrigues, Jéssica Maria Camargo Borba, Amanda Homse Netto, \\ Marina Sconzo Polydoro and Daniel Guimarães Tiezzi ${ }^{*}$ (i)
}

\begin{abstract}
Background: Axillary lymph node involvement is one important prognostic factor in breast cancer, but the way to access this information has been modified over the years. This study evaluated if axillary ultrasound (US) coupled with fine-needle aspiration cytology (FNAC) can accurately predict clinically relevant node metastasis in patients with breast cancer, and thus assist clinical decisions

Methods: This is a cross-sectional study with retrospective data collection of 241 individuals (239 women and 2 men) with unilateral operable breast cancer who were submitted to preoperative axillary assessment by physical exam, US and FNAC if suspicious nodes by imaging. We calculated sensitivity, specificity, and accuracy of the methods. We compared the patient's characteristics using chi-square test, parametrics and non-parametrics statistics according to the variable.

Results: The most sensible method was US $(0.59 ; 95 \% \mathrm{Cl}, 0.50-0.69)$, and the most specific was US coupled with FNAC $(0.97 ; 95 \% \mathrm{Cl}, 0.92-0.99)$. Only $2.7 \%$ of the patients with normal axillary US had more than 2 metastatic nodes in the axillary lymph node dissection, against $50 \%$ of the patients with suspicious lymph nodes in the US and positive FNAC.

Conclusions: Axillary US coupled with FNAC can sort patients who have a few metastatic nodes at most from those with heavy axillary burden and could be one more tool to initially evaluate patients and define treatment strategies.
\end{abstract}

Keywords: Breast cancer, Lymph node metastasis, Axillary ultrasound, Fine-needle aspiration cytology

\section{Background}

Breast cancer is the most common malignancy among women all over the world and responsible for almost 500,000 deaths each year [1]. Axillary lymph node

\footnotetext{
* Correspondence: dtiezzi@usp.br

Department of Gynecology and Obstetrics, Breast Disease Division, Ribeirão Preto Medical School, University of São Paulo, Avenida Bandeirantes 3.900, Monte Alegre, Ribeirao Preto, São Paulo, SP, Brazil
}

involvement is one important prognostic factor, but the way to access them has modified over the years [2]. Axillary lymph node dissection (ALND) was performed routinely by William Halsted [3] with great morbidity, especially lymphedema and loss of arm function. In the 1990s, the sentinel node biopsy (SLNB) emerged, leading to the same important prognostic information and minimal morbidity, becoming the standard of care in the

(c) The Author(s). 2021 Open Access This article is licensed under a Creative Commons Attribution 4.0 International License, which permits use, sharing, adaptation, distribution and reproduction in any medium or format, as long as you give appropriate credit to the original author(s) and the source, provide a link to the Creative Commons licence, and indicate if changes were made. The images or other third party material in this article are included in the article's Creative Commons licence, unless indicated otherwise in a credit line to the material. If material is not included in the article's Creative Commons licence and your intended use is not permitted by statutory regulation or exceeds the permitted use, you will need to obtain permission directly from the copyright holder. To view a copy of this licence, visit http://creativecommons.org/licenses/by/4.0/ The Creative Commons Public Domain Dedication waiver (http://creativecommons.org/publicdomain/zero/1.0/) applies to the data made available in this article, unless otherwise stated in a credit line to the data. 
management of the axilla in clinically node-negative breast cancer patients [4].

More recently, the role of axillary dissection in sentinel node-positive, early breast cancer patients has been questioned by several trials, including Z0011. They found that ALND did not confer an advantage compared to SLNB in survival nor recurrence, in a subset of T1-2 patients with no palpable adenopathy and 1 or 2 metastatic lymph nodes [5].

Following this trend, non-invasive, less invasive, and costly methods to access the axilla have been studied. Baran et al. found PET/CT and MRI to be highly specific methods (93.18\% and $93.75 \%$, respectively), although the sensitivity was not as high $(81.03 \%$ and $68.57 \%$, respectively) [6]. They also found that combining the methods can enhance specificity to $97.67 \%$ and sensitivity to 83.05\%. Using diffusion-weighted imaging (DWI) as an advanced technology of MRI can enhance the accuracy of the method in detecting metastatic axillary lymph nodes as demonstrated by Sui et al [7]. It is important to highlight that these methods are expensive and not broadly available.

New technologies such as intradermal microbubbles and contrast-enhanced ultrasound are also currently under investigation [8-10]. It is a promising method to identify the sentinel node and to predict lymph node metastasis before surgery, but larger patient data and multicenter cohort trials are required to establish clinical utility.

Lymph node imaging alone is insufficiently specific to avoid SLNB and proceed directly to ALND; therefore, other strategies had to be developed [11]. The addition of fine-needle aspiration cytology (FNAC) or core needle biopsy to the US enhances the specificity of the method and is being used to assist clinical decisions on breast cancer treatment [12]. It is a relatively low-cost, quick, and well-tolerated procedure associated with minimal morbidity that can evaluate the axillary status preoperatively, sparing time, and costs of an unnecessary SLNB and helps clinicians to select patients that could benefit from NACT [12-14].

However, the utility of axillary US in recently diagnosed breast cancer patients has been questioned in the past few years because of the practice-changing ACOSOG Z0011 trial $[5,15]$. They found that ALND did not confer an advantage compared to SLNB in survival nor recurrence, in a subset of T1-2 patients with no palpable adenopathy and 1 or 2 metastatic lymph nodes [5]. Thus, proceeding to ALND after suspicious US and positive FNAC could lead to overtreatment in this subset of Z0011 patients [15].

The aim of our study was to evaluate if axillary US coupled with FNAC of the suspicious nodes can better predict lymph node metastasis than physical exam in patients with breast cancer. Moreover, we evaluated if axillary US and FNAC can sort patients with a clinically relevant heavy nodal burden from those with minimal or little lymph node involvement.

\section{Methods \\ Study design}

This is a cross-sectional study with retrospective data collection that included patients with invasive breast cancer who were submitted to preoperative axillary ultrasound. The patients were assessed and treated at the Breast Diseases Division of Hospital das Clínicas of Ribeirão Preto Medical School, University of São Paulo, from August 2015 to November 2019. Patients were excluded if they did not undergo surgery, if they underwent neoadjuvant treatment, if they had distant metastasis, or had tumors that were not primarily from the breast (Fig. 1). Three patients with suspicious lymph nodes in the US that were not submitted to FNAC were included only in the ultrasound analysis. All patients underwent axillary surgery (SLNB or ALND).

\section{Protocol of preoperative axillary assessment}

All patients underwent clinical assessment and axillary ultrasound before treatment. The clinical assessment was performed by an experienced breast surgeon. Clinical axillary status was classified as N0 if no suspicious lymph node was identified, N1 if suspicious movable level I-II axillary lymph nodes were identified, or N2 if palpable suspicious level I-II axillary lymph nodes were clinically fixed or matted [16]. Patients with suspicious sonographic findings underwent FNAC of the most suspicious lymph node. FNAC results were either positive, negative, or inconclusive. For statistical analysis, inconclusive was interpreted as negative (non-positive).

\section{Ultrasound}

The patients were assessed by axillary ultrasound scan using a wide-band linear transducer within at least 4 to $11 \mathrm{MHz}$ range. The ultrasound systems used were Voluson 730 (GE Healthcare, Chicago, USA) until January 2018 and Voluson S10 (GE Healthcare, Chicago, USA) thereafter. All exams were performed by one breast surgeon or one radiologist, both with experience in breast ultrasound. We considered suspicious lymph nodes in the US, those with thickening of the cortex (larger than $3 \mathrm{~mm}$ ), eccentric medulla, or absent medulla (Fig. 2). The size of the lymph node was not considered because it is less specific than morphology [12, 17-19]. After the ultrasound, the nodes considered suspicious underwent guided FNAC. FNAC was performed in the most representative abnormal node. 


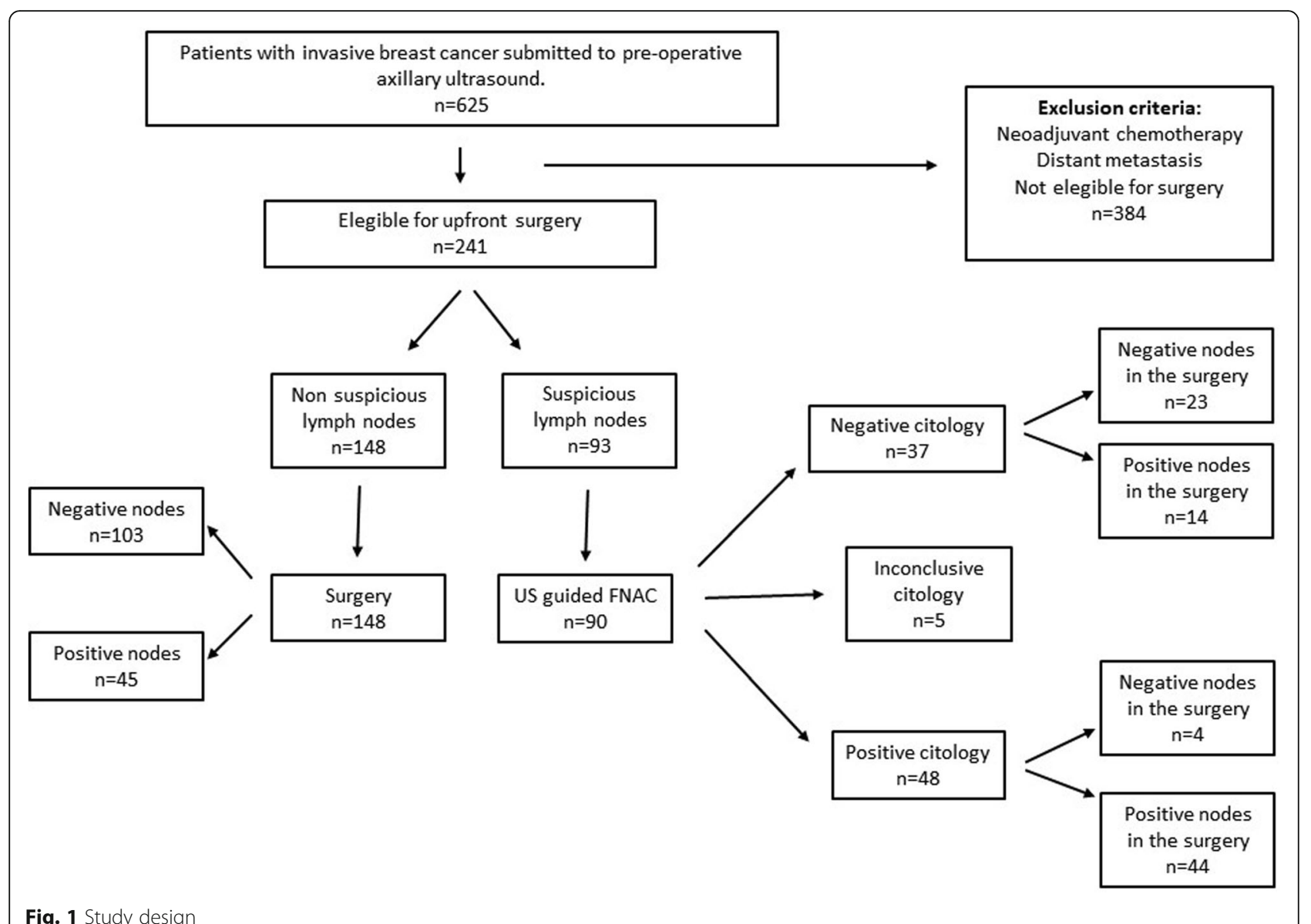

Fig. 1 Study design

\section{Statistical analysis}

We used the $\mathrm{R}$ software environment for statistical analysis version 4.0.2 (2020-06-22) and the packages dplyr, furniture, and epiR. Postoperative histology was the gold standard for axillary status. The characteristics of patients with positive and negative nodes were compared using chi-square and non-parametric or parametric statistics according to variable types. For diagnostic performance, we calculated the sensitivity, specificity, and accuracy of the physical exam, axillary US, and axillary US followed by FNAC when US was suspicious for metastasis. To calculate the diagnostic accuracy of ultrasound followed by FNAC, we compared the results of ultrasound and FNAC to the final pathology report (surgical specimen). The preoperative assessment of the axillary lymph nodes was considered negative if the patient had either a negative ultrasound or a suspicious ultrasound and a negative FNAC. The preoperative assessment of the axillary lymph nodes was considered positive if the patient had a suspicious ultrasound with a positive FNAC.

\section{Results}

A total of 241 patients ( 239 women and 2 men) with histologically confirmed unilateral breast cancer who underwent upfront were included. The characteristics of included patients according to the final axillary status are shown in Table 1.

Forty-six percent of the patients had at least one positive axillary lymph node. The distribution according to age and tumor characteristics (size, grade, and immunohistochemistry biomarkers) were similar between the two groups. The clinical assessment of axillary lymph nodes showed $\mathrm{cN} 1$ and $\mathrm{cN} 2$ were more frequent among patients with positive axillary lymph nodes.

The individual accuracy of clinical assessment, axillary ultrasound, and ultrasound combined with FNAC to detect axillary lymph node metastasis is shown in Table 2 . Adding FNAC to the axillary US did not modify the accuracy, because the increase in the specificity from 79 to 97\% was associated with the decrease of sensitivity from 59 to $40 \%$. Since the performance of the FNAC depends on the result of the US, the error of one method interferes with the result of the other, leading to a low sensitivity when combined.

Twenty-seven out of 91 patients that were clinically node-negative and did not have any suspicious lymph nodes in the US had metastatic nodes in the surgery: 18 patients with one positive node, 2 with micrometastasis, 


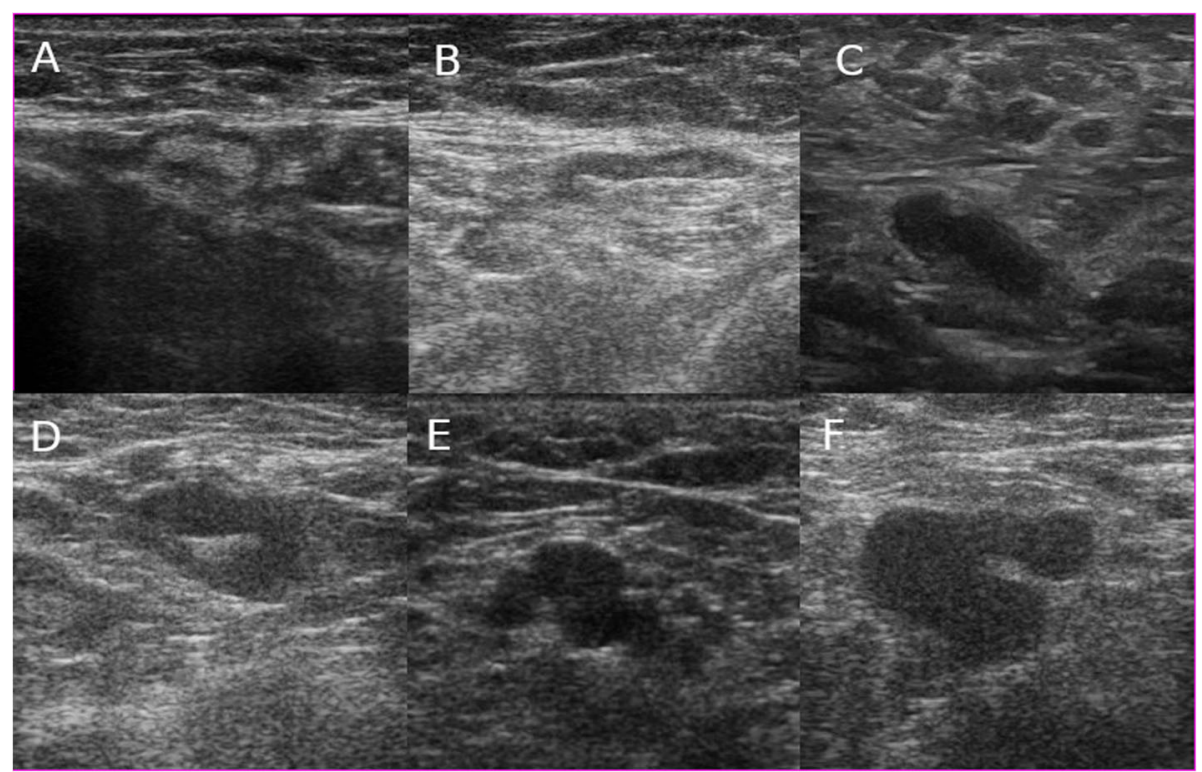

Fig. 2 Axillary lymph node ultrasound images. Non-suspicious lymph node in clinically node negative cN0 patient and non-metastatic nodes confirmed after ALND (A). Axillary lymph node with eccentric thickening of the cortex in the US, positive FNAC, and one metastatic lymph node in the ALND (B). Atypical lymph node in the US in a clinically N1 patient, with positive FNAC and one metastatic node in the ALND (C). Atypical lymph node with uniform cortical thickening $(>3 \mathrm{~mm})$ in a $\mathrm{CNO}$ patient with positive FNAC and more than three metastatic nodes in the ALND (D). Atypical lymph node with compressed fatty hilum and cortical thickening in a cNO patient with positive FNAC and $>3$ metastatic nodes in the ALND $(\mathbf{E})$. Irregular node with a mass-like appearance in a cNO patient, positive FNAC and $>3$ metastatic nodes in the ALND (F)

3 with two positive nodes, and 4 patients with more than two positive nodes.

We identified 99 patients that fit the ACOSOG Z0011 trial criteria: $\mathrm{T} 1$ or $\mathrm{T} 2, \mathrm{cN} 0$, submitted to conservative surgery followed by radiation therapy. All of them had a preoperative axillary ultrasound. Only four patients (4\%) had suspicious lymph nodes in the US and positive FNAC, but up to two metastatic nodes in the dissection. These four patients were overtreated according to the results from the ACOSOG Z0011 trial, because of the results of the US and FNAC.

On the other hand, we identified 13 patients that were clinically N1 or N2 but had non-suspicious nodes in the ultrasound and underwent sentinel node biopsy. Seven of these patients had no metastatic nodes, 2 had exclusive micrometastatic disease, and 2 had up to two metastatic lymph nodes and did not get axillary dissection. These 11 patients (17\% of the $N+$ patients) had treatment deescalated because of the preoperative axillary ultrasound.

Suspicious axillary lymph nodes in the US and positive FNAC were associated with a heavier axillary burden. Among the 148 patients with normal axillary ultrasound, only 4 (2.7\%) had more than 2 metastatic lymph nodes, while among the 93 with atypical lymph nodes in the US, thirty-two (34\%) had more than 2 metastatic nodes $(p<0.005)$. Moreover, among the 48 patients with positive FNAC, $24(50 \%)$ had more than 2 axillary lymph nodes with metastasis $(p<0.005)$. Figure 3 shows the percentage of patients with more than three metastatic nodes in the ALND according to the clinical assessment, axillary US result, and FNAC result.

\section{Discussion}

Axillary lymph node involvement is an important prognostic factor in breast cancer [20-23]. It is well known that the accuracy of physical examination alone is limited [24]; therefore, alternative methods are being investigated to effectively assess the axillary lymph node status with minimal morbidity and low cost. All preoperative methods used in this study (physical exam, axillary US, and FNAC) missed metastatic axillary lymph nodes.

Physical exam and axillary ultrasound are able to predict accurately a low axillary lymph node involvement (less than 3 metastatic nodes), but the false-negative rate of the methods does not obviate the need for SLNB [11, $25]$. It is interesting to note that almost $96 \%$ of our patients with no suspicious nodes in the physical exam and the US had less than three positive nodes in the surgery. Now, it is not yet clear if that is enough information to tailor the adjuvant treatment [26]. The ongoing SOUND trial (NCT02167490) is prospectively evaluating if preoperative imaging of the axilla in early breast cancer patients can identify patients with clinically relevant nodal burden and safely spare patients from SLN biopsy [27]. 
Table 1 Characteristics of patients according to the final axillary status

\begin{tabular}{|c|c|c|c|}
\hline $\begin{array}{l}\text { Variable } \\
\text { Number of cases }\end{array}$ & $\begin{array}{l}\text { Negative nodes } \\
n=130\end{array}$ & $\begin{array}{l}\text { Positive nodes } \\
n=111\end{array}$ & $p$-value \\
\hline Age (range) & $61.0(31-88)$ & $58.3(27-88)$ & 0.081 \\
\hline \multicolumn{4}{|l|}{ Tumor size $(T)$} \\
\hline $1 a$ & $1(0.8 \%)$ & $1(0.9 \%)$ & \multirow[t]{7}{*}{0.111} \\
\hline $1 b$ & 19 (14.6\%) & $5(4.5 \%)$ & \\
\hline $1 c$ & 57 (43.8\%) & 59 (53.2\%) & \\
\hline 2 & 46 (35.4\%) & 39 (35.1\%) & \\
\hline 3 & $2(1.5 \%)$ & $0(0 \%)$ & \\
\hline $4 b$ & $4(3.1 \%)$ & $3(2.7 \%)$ & \\
\hline Missing & $1(0.8 \%)$ & $4(3.6 \%)$ & \\
\hline \multicolumn{4}{|c|}{ Clinical lymph nodes } \\
\hline No & $110(84.6 \%)$ & 65 (58.6\%) & \multirow[t]{4}{*}{$<.001$} \\
\hline N1 & $17(13.1 \%)$ & $40(36 \%)$ & \\
\hline N2 & $1(0.8 \%)$ & $6(5.4 \%)$ & \\
\hline Missing & $2(1.5 \%)$ & $0(0 \%)$ & \\
\hline \multicolumn{4}{|l|}{ Ultrasound } \\
\hline Normal & $103(79.2 \%)$ & 45 (40.5\%) & \multirow[t]{2}{*}{$<.001$} \\
\hline Suspicious & $27(20.8 \%)$ & $66(59.5 \%)$ & \\
\hline \multicolumn{4}{|l|}{ Tumor grade } \\
\hline 1 & $40(30.8 \%)$ & $28(25.2 \%)$ & \multirow[t]{4}{*}{0.601} \\
\hline 2 & 70 (53.8\%) & $64(57.7 \%)$ & \\
\hline 3 & $17(13.1 \%)$ & $17(15.3 \%)$ & \\
\hline Missing & $3(2.3 \%)$ & $2(1.8 \%)$ & \\
\hline \multicolumn{4}{|l|}{ Estrogen receptor } \\
\hline Negative & $23(17.7 \%)$ & $12(10.8 \%)$ & \multirow[t]{2}{*}{0.184} \\
\hline Positive & $107(82.3 \%)$ & 99 (89.2\%) & \\
\hline \multicolumn{4}{|c|}{ Progesterone receptor } \\
\hline Negative & $42(32.3 \%)$ & 35 (31.5\%) & \multirow[t]{2}{*}{1} \\
\hline Positive & 88 (67.7\%) & $76(68.5 \%)$ & \\
\hline \multicolumn{4}{|l|}{ HER 2} \\
\hline Negative & $111(85.4 \%)$ & 98 (88.3\%) & \multirow[t]{2}{*}{0.637} \\
\hline Positive & 19 (14.6\%) & $13(11.7 \%)$ & \\
\hline \multicolumn{4}{|l|}{ Ki 67} \\
\hline Negative & 41 (31.5\%) & 39 (35.1\%) & \multirow[t]{3}{*}{0.54} \\
\hline Positive & $78(60 \%)$ & $60(54.1 \%)$ & \\
\hline Missing & $11(8.5 \%)$ & $12(10.8 \%)$ & \\
\hline \multicolumn{4}{|l|}{ Surgery } \\
\hline Mastectomy & 49 (37.7\%) & 48 (43.2\%) & \multirow[t]{2}{*}{0.457} \\
\hline Tumorectomy & 81 (62.3\%) & 63 (56.8\%) & \\
\hline
\end{tabular}

On the other side, patients with palpable adenopathy are at a higher risk of having massive axillary involvement and are managed either with upfront ALND or, increasingly, neoadjuvant chemotherapy [28]. Our data are in accordance since half of our cN1/N2 patients had positive nodes at the final pathology assessment even with a normal ultrasound imaging. It is relevant to highlight the small number of patients in this scenario, since most of the $\mathrm{cN} 1 / \mathrm{N} 2$ patients in our institution go to neoadjuvant therapy.

The sensitivity of the US alone is admittedly low, varying from 26.4 to $75.9 \%$, as well as the sensitivity of other imaging methods such as PET-CT that varies from 35 to 85\% [11]. Our findings are in accordance with the literature; the sensitivity of the US alone to detect axillary lymph node metastasis was $59 \%$.

Before deciding about scalonating treatment (local or systemic) because of a suspicious lymph node image, it is essential to confirm the finding with FNAC or core needle biopsy (CNB) [29]. The PPV of the US alone is not high enough to directly proceed to ALND without tissue sampling, ranging from 56 to $90 \%[29,30]$. Our data are in accordance; we found a PPV of US of $71 \%$. FNAC was particularly useful though to confirm a metastatic lymph node when ultrasound was suspicious since the specificity of US was $79 \%$ while the specificity of US coupled with FNAC was $97 \%$.

The absence of neoplastic cells on FNAC in ultrasound suspicious nodes did not exclude completely a malignant node. In our study, we had 17/61 patients with metastatic nodes in the surgical specimen that had suspicious nodes in the US and a false-negative FNAC result, leading to a false-negative (FN) rate of $28 \%$. This is a recognized limitation of the method due to inadequate sampling, preparation, or interpretation of the material. In the literature, the FN rate of US-FNAC ranges from 9 to $41 \%$ [31]. In daily practice, US-FNAC/ $\mathrm{CNB}$ are performed only for patients with suspicious nodes in the US, which leads to an even higher FN rate if the images are not interpreted properly [31]. Despite the great effort made to diminish the false-negative rate of FNAC, it remains too high to omit definitive surgical staging of the axilla [25]. A meta-analysis comparing the diagnostic accuracy of FNAC and CNB showed an increased sensitivity for the latter and similar very high specificity for both methods [31]. FNAC has various advantages though, including minimal invasiveness, safety, and low cost [31].

Patients with suspicious US and positive FNAC were more likely to have a higher disease burden than those with positive sentinel nodes alone and therefore represent a distinct patient population that should be addressed carefully [32].

The accuracy of the method is high enough to sort patients that have a few metastatic lymph nodes at most from those with a heavy axillary burden (three or more positive nodes) $[15,20,26]$. Our findings are highly in accordance, since among the clinically node-negative 
Table 2 Accuracy of diagnostic methods for axillary status considering any positive node in the surgery

\begin{tabular}{llll}
\hline Method & Clinical & Ultrasound & Ultrasound and FNAC \\
\hline Sensitivity & $0.41(0.32,0.51)$ & $0.59(0.50,0.69)$ & $0.40(0.30,0.49)$ \\
Specificity & $0.86(0.79,0.91)$ & $0.79(0.71,0.86)$ & $0.97(0.92,0.99)$ \\
PPVa & $0.72(0.59,0.82)$ & $0.71(0.61,0.80)$ & $0.92(0.80,0.98)$ \\
NPVb & $0.63(0.55,0.70)$ & $0.70(0.62,0.77)$ & $0.65(0.58,0.72)$ \\
Diagnostic accuracy & $0.65(0.59,0.71)$ & $0.70(0.64,0.76)$ & $0.70(0.64,0.76)$ \\
\hline
\end{tabular}

aPPV positive predictive value, $b N P V$ negative predictive value

patients with normal US, only $2 \%$ had more than 3 metastatic lymph nodes in the surgical specimen while among the patients with suspicious nodes in the ultrasound and positive FNAC, $57 \%$ had massive axillary lymph node involvement. In this context, the methods could help sort patients with a high axillary burden that can benefit from neoadjuvant therapy, including deescalating axillary surgery.

To our understanding, axillary evaluation of breast cancer patients is an evolving topic, and axillary US coupled with FNAC could be a less invasive, highly available strategy used to define therapy.

It is relevant to highlight the possible limitations of the methods, including a reasonably high false-negative rate even when combining physical exam and US [12] and the possible axillary surgical overtreatment created by a positive FNAC in the ACOSOG Z0011 context [15]. The extent of this harm is not consensual yet. While some authors found a great number of patients undergoing unnecessary ALND because of a suspicious image and positive cytology/pathology [33], others observed that patients with a high nodal burden are those that have positive FNAC or CNB [34]. Our findings are in accordance with the latter. Only $4 \%$ of the patients with suspicious US and positive FNAC would have fit the ACOSOG Z0011 criteria and were overtreated with ALND in our study.

This study has some limitations that need to be addressed, such as the retrospective nature. Another relevant limitation of the present study is that ultrasound is highly operator dependent [35], and even though it is interesting to know the results of the methods in the daily practice, the reproducibility was not evaluated. Lastly, the lymph nodes submitted to US-guided FNAC were not routinely clipped, and therefore, it is not possible to conclude that they were retrieved in the axillary surgery.

It would be interesting to look forward to whether the association of axillary US to other imaging techniques such as mammography, MRI, and PET-CT could enhance the sensibility of the method and assist clinical decisions.

\section{Conclusion}

Axillary US coupled with FNAC can sort patients that have a few metastatic nodes at most from those with

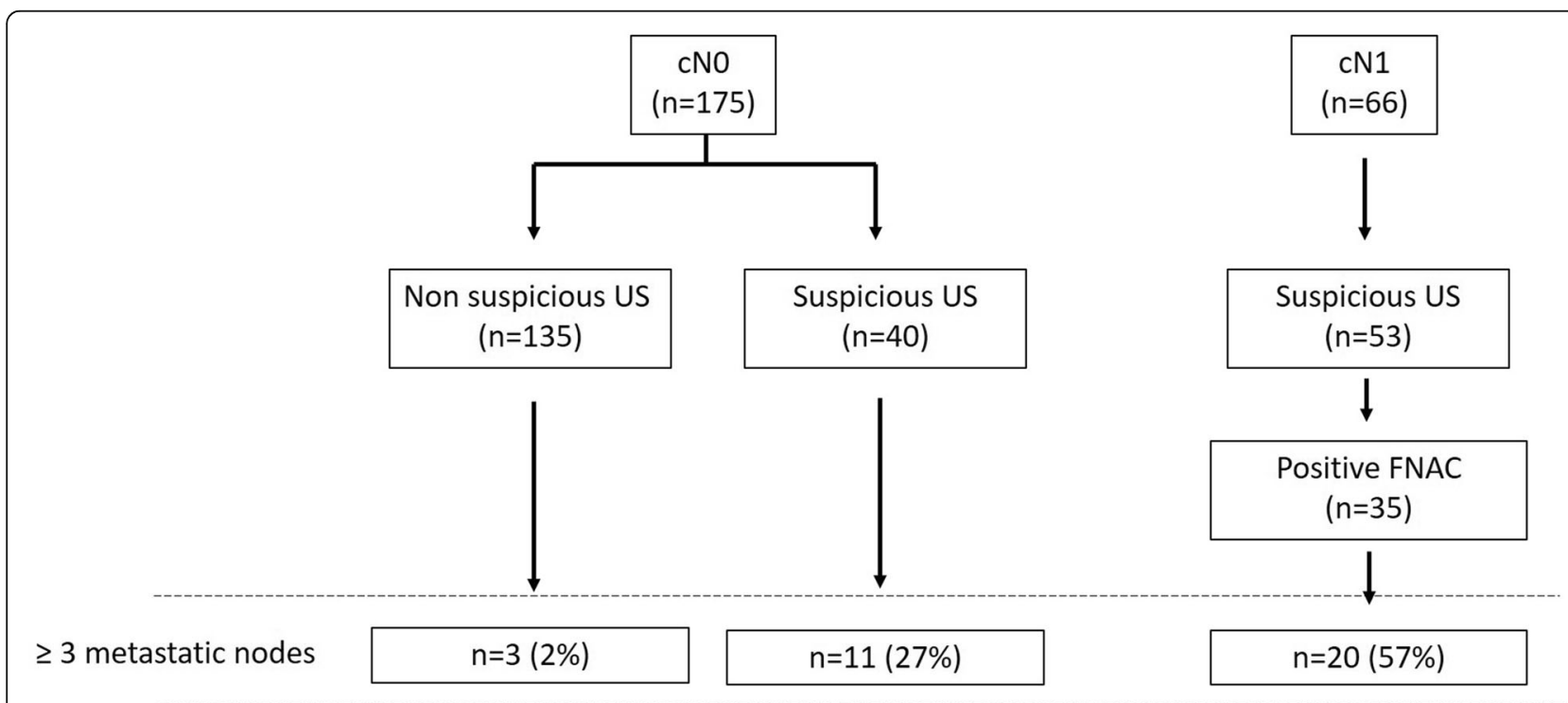

Fig. 3 Massive axillary involvement according to the clinical status and US imaging. Percentage of patients with high axillary burden ( $\geq 3$ metastatic nodes in the ALND) according to the clinical assessment, axillary US result, and FNAC result 
heavy nodal burden and could be one more tool to initially evaluate patients and define treatment strategies as well as sort patients that can benefit from neoadjuvant therapy.

\section{Abbreviations}

ALND: Axillary lymph node dissection; CNB: Core needle biopsy; cNO: Clinically node-negative; DWI: diffusion-weighted imaging; FN: False negative; FNAC: Fine-needle aspiration cytology; MRI: Magnetic resonance imaging; NACT: Neoadjuvant chemotherapy; NPV: Negative predictive value; PET/CT: Positron emission tomography/computed tomography; PPV: Positive predictive value; SLN: Sentinel lymph node; SLNB: Sentinel lymph node biopsy; US: Ultrasound

\section{Acknowledgements}

Not applicable.

\section{Authors' contributions}

IPCB - substantial contributions to the conception and design of the work; acquisition, analysis, and interpretation of the data; and drafting of the work. FJCR - substantial contributions to the conception of the work, analysis and interpretation of the data, and revision for critically important intellectual content. JMA-substantial contributions to the conception of the work and revision for critically important intellectual content. TCGFR—substantial contributions to the acquisition, analysis, and interpretation of the data for the work and revision for critically important intellectual content JMCB — substantial contributions to the acquisition, analysis, and interpretation of the data for the work and revision for critically important intellectual content. AHN—substantial contributions to the acquisition, analysis, and interpretation of the data for the work and revision for critically important intellectual content. MSP_-substantial contributions to the acquisition, analysis, and interpretation of the data for the work and revision for critically important intellectual content. DGT-substantial contributions to the conception and design of the work, analysis and interpretation of the data, and revision of the work for critically important intellectual content. The authors read and approved the final manuscript.

\section{Funding}

The authors did not receive any financial support for the research, authorship, and/or publication of this article.

\section{Availability of data and materials}

The datasets used and/or analyzed during the current study are available from the corresponding author on reasonable request.

\section{Declarations}

\section{Ethics approval and consent to participate}

The study was approved by the Institutional Ethics Committee, and the informed consent was waived (CAAE: 49843815.8.0000.5440).

\section{Consent for publication}

Not applicable.

\section{Competing interests}

The authors declare that they have no competing interests.

Received: 18 June 2021 Accepted: 2 September 2021

Published online: 28 September 2021

\section{References}

1. Ban K, Godellas C. Epidemiology of Breast Cancer. Surg Oncol Clin N Am. 2014;23:409-22.

2. Yan M, Abdi MA, Falkson C. Axillary Management in Breast Cancer Patients: A Comprehensive Review of the Key Trials. Clin Breast Cancer. 2018;18(6): e1251-9.

3. Halsted WS. I. The Results of Operations for the Cure of Cancer of the Breast Performed at the Johns Hopkins Hospital from June, 1889, to January, 1894. Ann Surg. 1894;20(5):497-555.
4. Magnoni F, Galimberti V, Corso G, Intra M, Sacchini V, Veronesi P. Axillary surgery in breast cancer: An updated historical perspective. Semin Oncol. 2020;47(6):341-52.

5. Giuliano AE, Ballman K, McCall L, Beitsch P, Whitworth PW, Blumencranz P, et al. Locoregional Recurrence After Sentinel Lymph Node Dissection With or Without Axillary Dissection in Patients With Sentinel Lymph Node Metastases: Long-term Follow-up From the American College of Surgeons Oncology Group (Alliance) ACOSOG Z0011 Randomized Trial. Ann Surg. 2016;264(3):413-20.

6. Baran MT, Gundogdu H, Demiral G, Kupik O, Arpa M, Pergel A. PET-CT and MR Imaging in the Management of Axillary Nodes in Early Stage Breast Cancer. J Coll Physicians Surg Pak. 2020;30(9):946-50.

7. Sui WF, Chen X, Peng ZK, Ye J, Wu JT. The Diagnosis of Metastatic Axillary Lymph Nodes of Breast Cancer By Diffusion Weighted Imaging: a metaanalysis and systematic review. World J Surg Oncol. 2016;14(1):155.

8. Xie F, Zhang D, Cheng L, Yu L, Yang L, Tong F, et al. Intradermal microbubbles, and contrast-enhanced ultrasound (CEUS) is a feasible approach for sentinel lymph node identification in early-stage breast cancer. World J Surg Oncol. 2015;13(1):319.

9. Wang Y, Zhou W, Li C, Gong H, Li C, Yang N, et al. Variation of sentinel lymphatic channels (SLCS) and sentinel lymph nodes (SLNs) assessed by contrast-enhanced ultrasound (CEUS) in breast cancer patients. World J Surg Oncol. 2017, 15(1):127.

10. Cui Q, Dai L, Li J, Xue J. Accuracy of CEUS-guided sentinel lymph node biopsy in early-stage breast cancer: a study review and meta-analysis. World J Surg Oncol. 2020;18(1):112.

11. Kwak HY, Chae BJ, Bae JS, Kim EJ, Chang EY, Kim SH, et al. Feasibility of sentinel lymph node biopsy in breast cancer patients clinically suspected of axillary lymph node metastasis on preoperative imaging. World J Surg Oncol. 2013;11(1):104.

12. Marino MA, Avendano D, Zapata P, Riedl CC, Pinker K. Lymph Node Imaging in Patients with Primary Breast Cancer: Concurrent Diagnostic Tools. Oncologist. 2020;25(2):e231-42.

13. Gipponi M, Fregatti P, Garlaschi A, Murelli F, Margarino C, Depaoli F, et al. Axillary ultrasound and Fine-Needle Aspiration Cytology in the preoperative staging of axillary node metastasis in breast cancer patients. Breast Edinb Scotl. 2016;30:146-50.

14. Cheng Y-S, Kuo S-J, Chen D-R. Sparing sentinel node biopsy through axillary lymph node fine needle aspiration in primary breast cancers. World I Surg Oncol. 2013;11(1):296.

15. Black D. Axillary Ultrasound: For All, for None, to Diagnose Positive Nodes, or to Support Avoiding Sentinel Lymph Node Biopsy Altogether. Ann Surg Oncol. 2017;24(1):64-9.

16. Amin MB, Greene FL, Edge SB, Compton CC, Gershenwald JE, Brookland RK, et al. The Eighth Edition AJCC Cancer Staging Manual: Continuing to build a bridge from a population-based to a more "personalized" approach to cancer staging. CA Cancer J Clin. 2017;67(2):93-9.

17. Lowes S, Leaver A, Cox K, Satchithananda K, Cosgrove D, Lim A. Evolving imaging techniques for staging axillary lymph nodes in breast cancer. Clin Radiol. 2018;73(4):396-409.

18. Lee B, Lim AK, Krell J, Satchithananda K, Coombes RC, Lewis JS, et al. The Efficacy of Axillary Ultrasound in the Detection of Nodal Metastasis in Breast Cancer. Am J Roentgenol. 2013;200(3):W314-20.

19. Zhu Y, Zhou W, Zhou J, Fei X, Ye T-J, Huang O, et al. Axillary Staging of Early-Stage Invasive Breast Cancer by Ultrasound-Guided Fine-Needle Aspiration Cytology. J Ultrasound Med. 35(5):885-93.

20. Maráz R, Zombori T, Ambrózay É, Cserni G. The role of preoperative axillary ultrasound and fine-needle aspiration cytology in identifying patients with extensive axillary lymph node involvement. Eur J Surg Oncol J Eur Soc Surg Oncol Br Assoc Surg Oncol. 2017;43(11):2021-8.

21. Nemoto T, Vana J, Bedwani RN, Baker HW, McGregor FH, Murphy GP. Management and survival of female breast cancer: results of a national survey by the American College of Surgeons. Cancer. 1980; 45(12):2917-24

22. Carter $\mathrm{CL}$, Allen $\mathrm{C}$, Henson DE. Relation of tumor size, lymph node status, and survival in 24,740 breast cancer cases. Cancer. 1989;63(1):181-7.

23. Clarke M, Collins R, Darby S, Davies C, Elphinstone P, Evans V, et al. Wang Y; Early Breast Cancer Trialists' Collaborative Group (EBCTCG). Effects of radiotherapy and of differences in the extent of surgery for early breast cancer on local recurrence and 15-year survival: an overview of the randomised trials. Lancet. 2005;366(9503):2087-106. 
24. Sacre RA. Clinical evaluation of axillar lymph nodes compared to surgical and pathological findings. Eur J Surg Oncol J Eur Soc Surg Oncol Br Assoc Surg Oncol. 1986;12(2):169-73.

25. Choi JS, Kim MJ, Moon HJ, Kim E-K, Yoon JH. False Negative Results of Preoperative Axillary Ultrasound in Patients with Invasive Breast Cancer: Correlations with Clinicopathologic Findings. Ultrasound Med Biol. 2012; 38(11):1881-6

26. Boland MR, Ni Cearbhaill R, Fitzpatrick K, Walsh SM, Evoy D, Geraghty J, et al. A Positive Node on Ultrasound-Guided Fine Needle Aspiration Predicts Higher Nodal Burden Than a Positive Sentinel Lymph Node Biopsy in Breast Carcinoma. World J Surg. 2016:40(9):2157-62.

27. Gentilini O, Veronesi U. Abandoning sentinel lymph node biopsy in early breast cancer? A new trial in progress at the European Institute of Oncology of Milan (SOUND: Sentinel node vs Observation after axillary UltraSouND). Breast Edinb Scotl. 2012;21(5):678-81.

28. McCartan D, Stempel M, Eaton A, Morrow M, Pilewskie M. Impact of Body Mass Index on Clinical Axillary Nodal Assessment in Breast Cancer Patients. Ann Surg Oncol. 2016;23(10):3324-9.

29. Jamaris S, Jamaluddin J, Islam T, See MH, Fadzli F, Rahmat K, et al. Is preoperative axillary ultrasound alone sufficient to determine need for axillary dissection in early breast cancer patients? Medicine (Baltimore). 2021; 100(19):e25412.

30. Chen MY, Gillanders WE. Staging of the Axilla in Breast Cancer and the Evolving Role of Axillary Ultrasound. Breast Cancer Dove Med Press. 2021;13: $311-23$.

31. Pyo J-S, Jung J, Lee SG, Kim N-Y, Kang D-W. Diagnostic Accuracy of FineNeedle Aspiration Cytology and Core-Needle Biopsy in the Assessment of the Axillary Lymph Nodes in Breast Cancer-A Meta-Analysis. Diagn Basel Switz. 2020;10(9):717.

32. Boone BA, Huynh C, Spangler ML, Sumkin J, Johnson R, McGuire KP, et al. Axillary Lymph Node Burden in Invasive Breast Cancer: A Comparison of the Predictive Value of Ultrasound-Guided Needle Biopsy and Sentinel Lymph Node Biopsy. Clin Breast Cancer. 2015;15(5):e243-8.

33. Attieh M, Jamali F, Berjawi G, Saadeldine M, Boulos F. Shortcomings of ultrasound-guided fine needle aspiration in the axillary management of women with breast cancer. World J Surg Oncol. 2019;17(1):208.

34. Liang Y, Chen X, Tong Y, Zhan W, Zhu Y, Wu J, et al. Higher axillary lymph node metastasis burden in breast cancer patients with positive preoperative node biopsy: may not be appropriate to receive sentinel lymph node biopsy in the post-ACOSOG Z0011 trial era. World I Surg Oncol. 2019;17(1): 37.

35. Choi J-H, Kang BJ, Baek JE, Lee HS, Kim SH. Application of computer-aided diagnosis in breast ultrasound interpretation: improvements in diagnostic performance according to reader experience. Ultrason Seoul Korea. 2018; 37(3):217-25.

\section{Publisher's Note}

Springer Nature remains neutral with regard to jurisdictional claims in published maps and institutional affiliations.

Ready to submit your research? Choose BMC and benefit from:

- fast, convenient online submission

- thorough peer review by experienced researchers in your field

- rapid publication on acceptance

- support for research data, including large and complex data types

- gold Open Access which fosters wider collaboration and increased citations

- maximum visibility for your research: over $100 \mathrm{M}$ website views per year

At $\mathrm{BMC}$, research is always in progress.

Learn more biomedcentral.com/submissions 